\title{
ЖУРНАЛИСТИКА
}

УДК 007:316.77-045.73

DOI 10.17223/19986645/34/14

\section{С.А. Водолазская}

\section{КОНВЕРГЕНЦИЯ КАК ИННОВАЦИОННЫЙ СПОСОБ ОРГАНИЗАЦИИ РАБОТЫ В СОВРЕМЕННОМ МЕДИАПРОСТРАНСТВЕ}

\begin{abstract}
В статье рассматривается важная для современного медиарынка категория - конвергентная редакция. На основании изучения научных исследований отечественных $u$ зарубежных ученых и анализа медиасреды сделана попытка выделить типичные модели конвергентных редакций, а также проанализировать специифику их функиионирования на примере национального рынка. Проведенное исследование анонсирует формат работь редакций основных игроков украинского информационного пространства, что позволяет говорить о необходимости осмысления их деятельности с позиций изучения модели организации медиа.

Ключевые слова: конвергентная редакция, переходнье медиа, объединенные медиа, конвергенция.
\end{abstract}

Современные медиакоммуникации - активно изменяющееся пространство, подверженное воздействию множества факторов, которые определяют последующий вектор развития. Достижения научно-технического прогресса, возросший запрос на оперативный доступ к информации, увеличение медиаактивности населения, появление Интернета приводят к необходимости оценки эффективности принципов и организационных моделей функционирования редакций газетных издательств, которые применяют многочисленные технические и технологические инновации, привносящие изменения во все этапы подготовки информационного издательского продукта. Происходит пересмотр традиционных схем работы газетно-журнальных редакций, что особенно важно в период нестабильного развития издательского бизнеса и вялой читательской активности. Появляется новое коммуникативное пространство, сориентированное на дигитализацию, интерактивную коммуникацию и персонализацию, несущее изменения в организацию рабочего процесса. Оценка интенсивности анонсированного изменения оценивается исследователями по-разному: сторонники первого подхода (Е. Баранова, Е. Вартанова, Г. Дженкинс) соотносят его с радикальными преобразованиями в отрасли, описывают конвергенцию на уровне макросистемы медиа; второго (Л. Дейли, М. Спиллман, М. Женченко) рассматривают их как процесс модернизации производства и генерирования контента, описывают интеграцию медиаплатформ, как важную составляющую конвергенции, на уровне создания конкретных бизнес-моделей. 
Несмотря на значительное внимание научного сообщества к понятию «конвергенция», присутствует скептицизм в оценке возможностей нового направления в медиа и незначительное внимание к его тенденциям со стороны журналистиковедов и теоретиков издательского бизнеса Украины, которые предпочитают заниматься исследованием особенностей функционирования традиционных СМИ и игнорируют мультиплатформные медиа, минимизируя изучение трансформаций традиционных редакций в условиях воздействия цифровых технологий.

Теоретическая база исследования. Несмотря на низкую активность в изучении феномена конвергенции в журналистике все же необходимо отметить значимость проведенных учеными исследований разных аспектов работы конвергентных СМИ, которыми занимались И. Аппельгрен, Е. Баранова, Е. Вартанова, И. Эрдал, О. Кайда, Ю. Лавриш, М. Луканина, В. Шеремет, В. Хелемендик, Т. Чилачава, Г. Яновский. Их исследования способствуют выявлению подходов, которые могут лежать в основе изучения процесса медиаконвергенции.

Цель статьи - провести исследование процесса медиаконвергенции и описать актуальные для украинского медиарынка модели функционирования конвергентных редакций в редакционно-издательском процессе.

Методы исследования. Исследование проводилось с использованием аналитического метода и системного подхода для изучения, систематизации, а также описания особенности внедрения возможностей бизнес-моделей, основанных на конвергенции.

Исследователи подчеркивают постепенный, на украинском рынке более медленный переход от моноплатформенной к конвергентной модели организации производства, сопровождаемой изменениями в философии медиапроизводства и медиапотребления. Внедрение технологических инноваций способствовало разработке новых средств для завоевания внимания массовой аудитории, что позволяет основной акцент делать на функциональности, подключая возможности дигитальной среды для размещения контента. На Украине присутствует глобальная конкуренция, о чем свидетельствуют и статистические данные Украинской ассоциации периодической прессы, в которых зарегистрированными, по состоянию на первую половину 2014 г., считаются 42573 печатных издания разной сферы распространения. Усложняют ситуацию и искушенность читателя, и его апатичность к печатной продукции, и увеличивающийся темпоритм жизни, предполагающий ориентацию на «клиповое мышление» и оперативно обновляемую информацию. Именно эти предпосылки и стали важным мотиватором введения целого ряда новшеств в работе редакционных коллективов украинских медиа. Подтверждением может стать утверждение теоретика медиаконвергенции Г. Дженкинса о необходимости ориентироваться на требования аудитории, которая воспринимает информацию на любой оперативно доступной платформе. Как ключевая должна восприниматься лексема «оперативно», так как именно эта категория становится определяющей при выборе потребителями информационного ресурса. Подготовка конвергентными СМИ контента для разных платформ, их миграционность способствуют росту их привлекательности и требуют пересмотра особенностей редакционной политики. 
Рассматривая примеры функционирования конвергентных редакций на украинском медиарынке, будем трактовать этот термин как модель работы редакции средств массовой информации, где используется принцип объединенной производственно-творческой структуры как способа управления коллективом с целью производства мультиплатформного медиаконтента.

Проанализировав существующие исследования по данной проблеме, пришли к выводу, что большинство ученых считают активное внедрение конвергентных моделей работы редакций вынужденным шагом медиакорпораций, связанным с борьбой против последствий экономического кризиса (О. Вартанова и В. Лейбин). В то же время считаем такой подход не комплексным, так как исследователями упускаются из виду технологическая и социальная составляющие, которые сыграли не менее существенную роль в процессе перехода к конвергентным редакциям.

В современной науке существует несколько вариантов классификации конвергентных редакций:

1. По уровню интегрированности выделяют две модели конвергентных редакций: интегрированную и кроссмедийную. Для первой характерны объединение печатной и онлайн-редакций, контроль над рабочим процессом, особый способ подачи материла с учетом особенностей различных платформ, наполнение платформ контентом усилиями редакционных отделов, а также предусмотрено дополнительное управление контентом в экстренных ситуациях. Кроссмедийная модель предполагает обязательное разделение рабочих процессов в печатной и онлайн-редакциях, но сохраняет их взаимодействие под контролем руководства. Классификация предложена в работах К. Майера [1].

2. По уровню интегрированности выделяют три модели конвергентных редакций: отдельные платформы, переходные медиа, полностью интегрированные медиа. Первая модель фиксирует отсутствие систематического сотрудничества и отстраненность в работе редакций разных медиа на всех этапах производства новостей. Вторая модель предполагает существование редакций для отдельных медиаплатформ, их деятельность курируется мультимедиа-координатором. Третья модель предполагает работу на основе полного объединения в единую редакцию архитектуры и инфраструктуры для мультиплатформного производства, а также контроль поступления информации и генерирование сообщений куратором. Классификация предложена в рамках исследования австрийских ученых «Ньюзрум конвергенция. Транснациональные корпорации» («Newsroom convergence. A transnational comparison») [2].

3. По типу организационной модели работы редакций СМИ: модель «автономной редакции», модель «конвергентной редакции». Классификация разработана украинской исследовательницей медиаконвергенции М. Женченко. Основой ее становится уровень функциональной и контентной конвергенции межредакционного сотрудничества [3].

С целью эффективного внедрения опыта зарубежных стран на украинский медиарынок и понимания специфики их работы необходимо говорить о том, что конвергентные процессы могут происходить на уровне производства контента и на уровне организационных структур. М. Женченко утверждает: 
«...в научном дискурсе модели редакционной деятельности СМИ в мультиплатформной среде выделяют одновременно по двум признаками: уровню конвергенции ньюзрумов и особенностям обмена контентом между разными платформами» [3. С. 81]. Считаем такую классификацию достаточно репрезентативной, способствующей выявлению основных направлений развития современной медиаиндустрии.

Теоретические обобщения и отсутствие прикладного их использования для изучения ситуации на украинском медиарынке стали движущим механизмом проведенного анализа. Для характеристики изданий была выбрана трикомпонентная классификация конвергентных редакций, в которой выделяем: модель работы редакций с полной интеграцией, модель переходных медиа и модель отдельных платформ. В каждой из этих моделей конвергенция происходит на уровне изменения структуры (структурная конвергенция), на уровне пересмотра моделей и объектов сотрудничества (тактическая конвергенция), на уровне изменения специфики рабочего потока (конвергенция рабочего процесса).

Анализ украинских изданий показал, что по модели «полной интеграции» конвергентной редакции работают редакции газет «День», «Kyiv Post», «Факты и комментарии», «Zaxid.net». Модель переходных медиа используют: газеты «Коммерсант», «Комментарии», «Украинский тиждень» и журналы «Фокус», «Forbes Украина». Модель отдельных платформ используется на украинском медиарынке достаточно редко, ее признаки присутствуют в работе редакций изданий «Корреспондент», «Сегодня». Каждое из названных изданий имеет онлайн-платформу. Редакция газеты «Украинский тиждень» работает над наполнением украино- и англоязычной версий интернет-портала «Тиждень.UA», как и газета «Комментарии» имеет веб-портал «Соmments.UA».

Примером объединения на базе печатного издания трех медиаплатформ можно назвать деятельность редакции газеты «День» (ежедневное всеукраинское издание общественно-политической тематики, выходит с 1996 г.), часть редакций работают над созданием нескольких печатных изданий, входящих в холдинг, например редакция газеты «День» работает над наполнением ежедневного печатного издания на украинском и русском языках и англоязычного дайджеста «The Day», сайта «День», проекта «Украина Incognita», приложения «Маршрут №1» и видеопроекта «День-ТБ». Все газетные статьи чаще всего зеркально переносятся на сайт в свободном доступе. Встречаем пример использования технической конвергенции, где главный акцент сделан на взаимодействии по созданию контента и обмену информацией. Редакция газеты состоит из более чем 30 штатных журналистов и редакторов, которые формируют совместный координационный отдел с целью контроля за работой веб-редакции и подготовкой печатного издания. Структурно редакция разделена на отделы, соответствующие рубрикам в газете («Политика», «Международная политика и информация», «Экономика», «Культура», «Общество», «История и Я», «СМИ и общественное мнение», «Корреспондентская сеть»), за наполнение которых отвечают редактор рубрики и штатные корреспонденты, несмотря на кажущуюся разобщенность редакций, объединяет их общее рабочее пространство, дающее возможность для взаимодейст- 
вия. Журналисты и редактор web-отдела работают над наполнением страниц в социальных сетях (Facebook, Twitter, Google+, ВКонтакте) наиболее актуальными и интересными материалами. Сайт газеты позволяет комментировать материалы, делиться ими в социальных сетях, пересылать по электронной почте.

Редакции информационно-аналитического еженедельника «Kyiv Post» работают над наполнением англоязычной версии печатного издания, а также русскоязычного и англоязычного сайта www.kyivpost.com и мобильной платформы (www.kyivpost.com.mobile). Русскоязычный сайт - это перевод материалов из англоязычной версии, но в планах редакции наполнение его оригинальным контентом. Структурно газета состоит из двух блоков: главный редакционный отдел - 4 сотрудника (главный редактор, редакторы рубрик «Новости», «Бизнес», «Стиль жизни»), основной отдел редакции. Над созданием контента печатной и электронной версий работает объединенная команда журналистов, собранные материалы оцениваются редакторами. Задание усложняется необходимостью обрабатывать созданные материалы для двух видов аудиторий - традиционной и интернет-ориентированной, со своими требованиями к способу оформления и передачи информации, для которых важны персонифицированность, интерактивность, мобильность, сегментированность. Данная специфика учитывается при наполнении медиаплатформы.

Редакции журнала «Фокус» работают над наполнением еженедельного русскоязычного журнала, ежедневно обновляемого новостного электронного издания, специальных проектов и рейтингов («100 влиятельных женщин», «200 влиятельных украинцев», «Лучшие города для жизни в Украине», «Современное искусство» и др.), специальных дополнений с аналитикой рынка недвижимости, технологий. Задача редактора новостной ленты - делать анонсы материалов в социальных сетях. Сайт «Фокуса» необходимо идентифицировать как самостоятельный новостной портал, где могут размещаться материалы из печатного издания, но большая часть контента оригинальная. Журналисты наделены правом выбирать платформу, для которой будут готовить материал. Перечень компетенций сотрудника разнообразен, обязательным является умение работать с фото-, видео-, аудиоматериалами.

Редакции «Forbes Украина» создают еженедельный печатный журнал, ежеквартальное специализированное приложение «Forbes Woman» и сайт www.forbes.ua, сайт «Forbes Conferences». Редакция печатного издания представлена главным редактором, шеф-редактором, двумя заместителями редактора, тремя редакторами главных отделов, двумя литературными реакторами и редактором IT, а также 2-3 корреспондентами на каждый отдел. Также в издании есть представитель распространенной в западных СМИ и уникальной для украинского медиарынка профессии - факт-чекер. Редакция интернет-портала состоит из шеф-редактора, редакторов отделов, редактора новостной ленты, фотокорреспондента и журналистов. Для привлечения внимания читателей на сайте используются twitter-трансляции, видеоинтервью, видеоанонсы материалов печатного издания.

По принципу объединенного ньюзрума свою деятельность осуществляют издания «Комментарии», «Украинский тиждень». Центральная и региональ- 
ные редакции «Комментариев» готовят еженедельное печатное информационно-аналитическое издание, двуязычный новостной портал «Comments.UA», собственный YouTube канал. Работа происходит в рамках одного ньюзрума, но с участием двух команд, которые придерживаются четкого распределения обязанностей. «Украинский тиждень» представлен печатным еженедельным журналом, интернет-порталом «Тиждень.UA».

Различаются способы работы редакций в украинских медиа. В газете «День» редакции разделены на рубрики, которые работают обособленно, находясь в одном помещении, выпускают контент для наполнения печатного издания, сайта и сопутствующих изданий. Газета «Kyiv Post» частично имитирует работу редакций по принципу скандинавской модели, использует стиль desk-редакции и отказывается от создания input и output отделов. Над материалами для печатной и электронной версий работает объединенная команда под руководством главного редактора, который выступает координатором. Работа редакции журнала «Фокус» - пример активного поиска комфортной модели функционирования, начальный этап - параллельное существование двух редакций, обслуживающих печатную и онлайн-платформы, которое постепенно оформилось в работу единого ньюзрума. Наблюдаем частичный обмен контентом между печатным изданием и сайтом, реже перепечатывание материалов с другой платформы с внесением минимальных правок. Генерирование информации ограничивается не конечным сроком, а исчерпанием новых информационных поводов (деталей).

Редакции изданий создают материалы на разных языках, наиболее распространенными являются русский и украинский, также встречаются материалы на английском языке. Печатные издания преимущественно выходят с использованием одного языка, но есть исключения: газета «День», «Зеркало недели» представлены в двух разноязыковых версиях.

Новые бизнес-стратегии изданий на украинском рынке представлены не в полном объеме, они сопряжены с изменениями качественных характеристик печатной продукции и процесса ее производства. Газетные редакции в условиях изменения форматов медиапотребления активно используют инновационные медиплатформы для генерирования контента (это и мобильная, PDA), но полностью игнорируют по техническим и экономическим причинам е-раper и kindle-платформы. К тому же при подготовке материалов для электронных версий периодической прессы или новостных интернет-порталов акцент смещен на развитие аудио- и видеоконтента. Аудиоконтент на сайтах украинских изданий может быть представлен в виде дополнений к фотографиям, как аудио-слайд-шоу, а также в формате комментариев к последним новостям. Мобильную версию имеют издания «m.day.kiev.ua» («День»), «mobile.tyzhden.ua» («Украинская неделя»), «kyivpost.com» («Kyiv Post»), «korrespondent.net» («Корреспондент»), «m.segodnya.ua» («Сегодня»). Мобильный телефон становится платформой для получения оперативного информационного и развлекательного контента, который может предоставляться читателю выборочно или в полном объеме. Приложение для смартфонов продуцирует редакция газеты «Комментарии», размещаются общие и региональные новости, что позволяет говорить о таргетированности аудитории, а также газета «Сегодня». Версия для мобильного телефона или смартфона 
значительно чаще практикуется на украинском медиарынке, редкостью остается версия для планшетов.

Для планшетов представляют отдельную версию газеты «Корреспондент», «Сегодня» (pda.segodnya.ua), а редакция последнего также работает над выпуском тематического еженедельного приложения для планшетных компьютеров «Мой уикенд». Газета «Сегодня» имеет в распоряжении собственный мультимедийный пресс-центр «Пресс-студия Сегодня Мультимедиа». Представители издания «Комментарии» запустили собственный YouTube канал, на котором размещают видеоматериалы собственного производства, а в разделе «Live Blog» публикуют видеоролики собственных корреспондентов о важных событиях в стране. Видео выполняет иллюстративную функцию и привязывается к статье с целью более полного отображения содержания статьи. Веб-редакция газеты «День» создала проект «День-ТБ». Львовский холдинг ТРК «Люкс» использует разные формы подачи контента - через Интернет (интернет-издание «Zaxid.net»), радио («Люкс») и телевидение (телевизионная редакция «Наш репортер» и новостной канал «24»). Разнообразные формы работы позволяют использовать принцип таргетированности аудитории, актуализируют информацию на ресурсе, способствуют расширению собственных возможностей. Преимущественно видеоконтент на сайтах газет и журналов представлен в виде непродолжительных вставочных сюжетов или последних новостей, снятых журналистами или читателями.

Актуальным элементом конвергентной политики стоит назвать использование современными украинскими медиа потенциала социальных сетей (наиболее популярными являются Facebook, Одноклассники, ВКонтакте, Google+) и блогов и микроблогов (Twitter). Преимущественно издания имеют странички параллельно в 2-3 социальных сетях. Читатели могут помочь расширить существующую в распоряжении издания информацию как размещая авторские видеоматериалы, так и оставляя событийные или уточняющие комментарии, что позволяет усовершенствовать и расширить методологию сбора и обработки информации. Ученые констатируют, что применение такого подхода создает «эффект масштаба».

Таблица 1. Представленность украинских новостных СМИ в социальных сетях

\begin{tabular}{l|c}
\hline \multicolumn{1}{c|}{ Название социальной сети и блога } & Количество представленных новостных СМИ, \% \\
\hline Facebook & 56 \\
\hline Одноклассники & 37 \\
\hline BКонтакте & 45 \\
\hline Google+ & 18 \\
\hline Blogspot & 7 \\
\hline
\end{tabular}

Для получения информации о представленности новостных средств массовой информации в социальных сетях были использованы данные, найденные через поисковые системы социальных сетей, и информация на страницах СМИ в Интернете, в исследовании приняли участие 400 украинских новостных средств массовой информации. Можно утверждать, что популярность социальных медиа как способа распространения информации среди печатных и электронных изданий недостаточна. 
Малораспространенным остается явление краудсорсинга - тенденции привлечения читателей ресурса к созданию новостей с использованием потенциала современных технологий через мобильный телефон или Интернет. Сайт «Корреспондент» инициировал создание рубрики «Я-корреспондент», где авторизированные читатели могут создавать собственные тексты, загружать видео и фото материалы. Сайт газеты «День» предложил рубрики «Обратная связь» и «Читатель «Дня» онлайн», основными заданиями которых является создание для читателей площадки для самореализации своих журналистских амбиций. Газета «Kyiv Post» предлагает читателям на неофициальной страничке в Facebook комментировать опубликованные материалы и предлагать идеи для новых.

Конвергенция в украинских средствах массовой информации преимущественно осуществляется посредствам интеграции печатной и интернетплатформ. Основное внимание уделяют развитию интернет-платформы, созданию видео- и аудиоконтента на сайте. Важный акцент редакциями сделан на распространении контента по существующим в распоряжении медиахолдингов медиаплатформам. В то время как анализ медиарынков Великобритании, Испании и США позволил Е. Барановой утверждать, что «долгая практика сотрудничества между редакциями газет и ТВ-каналов в США с появлением идей технологической конвергенции воплотилась в интеграцию на базе печатного издания трех медиаплатформ - газеты, кабельного ТВ-канала и интернет-ресурса, с целью совместного производства контента, обмена информационными ресурсами» [4. С. 91].

Анализ украинской периодической прессы свидетельствует, что большинство редакций выбирают модель переходного типа, редакции работают преимущественно над наполнением нескольких взаимодействующих информационных платформ. Характерными особенностями данной модели становятся активное взаимодействие в перекрестном анонсировании и размещении материалов на электронной или печатной платформе, практика отдельных редакций для каждой медиаплатформы, с собственным редактором новостей и мультимедиа-редактором. Объединенная модель конвергентной редакции встречается на украинском медиарынке редко, основной ее особенностью является создание единой редакции, которая координирует работу нескольких платформ. Модель «отдельных платформ» предполагает, независимо от выбранного способа передачи информации, существование каждого издания самостоятельно.

Таким образом, для развития украинских редакций периодической печати в условиях становления процесса конвергенции медиарынка характерна частая практика объединения на базе печатного издания преимущественно двух медиаплатформ - печатного издания и веб-сайта, значительно реже встречается трехкомпонентное объединение (печатное издание, веб-сайт и ТВканал), что позволяет говорить о внедрении принципа трансмедийного повествования с целью использования нескольких медиаплатформ для создания единого сообщения и сохранения самостоятельности материалов на разных носителях. Наблюдается высокий уровень развития интернет-платформы, которая становится самостоятельным медиаресурсом при сохранении взаимодействия по обмену информационными ресурсами, аудитория которой в 
количественном соотношении превышает аудиторию печатного издания. Присутствует использование различных каналов распространения контента. Стоит констатировать, что проведенный анализ украинского медиарынка показал, что чистой модели в работе не придерживается ни одна редакция, потому что явление конвергенции еще достаточно новое для средств массовой информации.

\section{Лumepamypa}

1. Майер K. Нужно объединять журналистов и разработчиков // Deutsche Welle Akademie. URL: http://onmedia.dw-akademie.de/russian (дата обращения: 22. 04. 2014).

2. Newsroom convergence: a transnational comparison / J. Garcia Aviles, A.Kaltenbrunner, D. Kraus, K. Meier, M. Carvajal. Medien haus Wien, 2008. P. 8-9. URL: https:// www.rtr.at/ de/ppf/ Kurzberichte2007/Konvergenz _ im_ Newsroom_Newsroom_Convergence.pdf (last accessed: 08.01.2014).

3. Женченко M.I. Організаційні моделі редакцій ЗМІ в умовах мультиплатформного медіавиробництва // Наукові записки інституту журналістики. 2014. Т. 55. С. 80-85.

4. Баранова E. Особенности развития газетных редакцый в условиях медиаконвергенции: дис. ... канд. филол. наук. М., 2011. 245 с.

\section{CONVERGENCE AS AN INNOVATIVE WAY OF ORGANIZING WORK IN THE MODERN MEDIA SPACE.}

Tomsk State University Journal of Philology, 2015, 2(34), pp. 174-183.

DOI 10.17223/19986645/34/14

Vodolazskaya Svetlana A., Kyiv National Taras Shevchenko University (Kyiv, Ukraine). E-mail: sveta@ddteam.net

Keywords: convergent editorial, transitional media, combined media convergence.

The article discusses convergent editing as the most important category of the modern media market as it has become a global challenge to the survival of the media and led to the emergence of a global change in the editorial and publishing process. Analysis of scientific works of Ukrainian and foreign researchers allowed to identify typical patterns of convergent editorials that occur in the global media practice. Processing of the source base has made it possible to conclude that the majority of editors can be classified according to the content production organization model. There has been allocated a transitional model, individual platforms and a full integration model. The main approaches to the study of the concept of media convergence have been identified and characterized. The future of the functioning of converged editorials in the Ukrainian media industry has been described. The study allowed to generalize the features of formation and functioning of domestic media editorials selected for analysis, as well as to clarify the features of the editing teams in the new environment. It has been proved that the process of combining different media gives editors an opportunity to build a new type of an editorial that rethinks traditional approaches to editing and publishing. The establishment of a multi-platform version has been recorded, which involves changing the content production process.

After analyzing the features of the Ukrainian editorials of informational-political publishers, it has been concluded that most of the editorials choose a transitional model and work in the format of two platforms, mainly on-line and print. This model is actively used for production process by Focus, Ukrainian Week, Comments, Forbes Ukraine. Newspapers Day and Kyiv Post use integration models. They organize the process of content production for multiple platforms in the format of a single editorial office. The model of individual platforms is used by editorials of Correspondent and Today.

Thus, the article allocates typical features of convergent editorials, establishes the fact of coexistence of electronic and print platforms with partial interaction in the exchange of content, announcement of materials. The main feature of the new business model becomes a statement of the availability of content without restrictions in time or territorial criteria. The development of the convergence process is based on the use of modern digital technologies, multimedia representation of content, single content production and its multiple distribution over different media platforms. 


\section{References}

1. Mayer K. Nuzhno ob"edinyat' zhurnalistov i razrabotchikov [We should unite journalists and developers]. Deutsche Welle Akademie. Available from: http://onmedia.dw-akademie.de/russian. (Accessed: 22nd April 2014).

2. Garcia Aviles J., Kaltenbrunner A., Kraus D., Meier K., Carvajal M. Newsroom convergence: a transnational comparison. Medien haus Wien, 2008, pp. 8-9. Available from: https://www.rtr.at/ de/ppf/Kurzberichte2007/Konvergenz_im_Newsroom_Newsroom_Convergence.pdf (Accessed: 08th January 2014).

3. Zhenchenko M.I. Organizatsiyni modeli redaktsiy ZMI v umovakh mul'tiplatformnogo mediavirobnitstva. Naukovi zapiski institutu zhurnalistiki, 2014, vol. 55, pp. 80-85. (In Ukrainian).

4. Baranova E. Osobennosti razvitiya gazetnykh redaktsyy v usloviyakh mediakonvergentsii: dis. kand. filol. nauk [Features of newspaper editorial board development in media convergence. Philology Cand. Diss.]. Moscow, 2011. 245 p. 